\title{
Intravenous Iron Replacement Therapy Improves Cardiovascular Outcomes in Hemodialysis Patients
}

\author{
MATTEO RIGHINI ${ }^{1}$, VITTORIO DALMASTRI ${ }^{2}$, IRENE CAPELLI ${ }^{1}$, CLAUDIO ORSI $^{2}$, \\ GABRIELE DONATI ${ }^{1}$, MARIA GIOVANNA PALLOTTI ${ }^{3}$, CHIARA PEDONE $^{3}$, \\ GIANNI CASELLA ${ }^{3}$, PASQUALE CHIECO ${ }^{4}$ and GAETANO LA MANNA ${ }^{1}$ \\ ${ }^{1}$ Department of Nephrology, Dialysis and Transplantation, Policlinico Sant'Orsola Malpighi, Bologna, Italy; \\ ${ }^{2}$ Department of Nephrology and Dialysis, Maggiore Hospital, Bologna, Italy; \\ ${ }^{3}$ Department of Cardiology, Maggiore Hospital, Bologna, Italy; \\ ${ }^{4}$ Department of Experimental, Diagnostic and Specialty Medicine (DIMES), University of Bologna, Bologna, Italy
}

\begin{abstract}
Background/Aim: More than half of deaths among hemodialysis patients are due to cardiovascular disease. This study examined whether intravenous administration of ferric carboxymaltose (FCM) has an impact on cardiovascular events in iron-deficient hemodialysis patients. Patients and Methods: We performed a retrospective study concerning patients undergoing hemodialysis in our center from September 2016 to December 2019. We identified those who began FCM therapy (FCM group) during this period and those who did not (control group). We analyzed clinical, echocardiographic and laboratory parameters at the beginning (t0) and after one year (t1), to detect differences between the two groups. Results: We identified 53 patients for the FCM group and 19 for the control group. Median follow-up was 1 year \pm 3 months for both groups. In the FCM group, we observed a reduction in the doses of erythropoiesis-stimulating agents (ESA) $(p<0.001)$ and a significative difference in cardiovascular events $(p<0.01)$, but no differences in echocardiographic parameters. Conclusion: Patients who received FCM reached satisfactory values of transferrin saturation and ferritin, presented fewer coronary artery events and cardiovascular events, and could reduce doses of ESA.
\end{abstract}

This article is freely accessible online.

Correspondence to: Gaetano La Manna, Nephrology, Dialysis and Renal Transplant Unit, S. Orsola Hospital Bologna, Via Massarenti 9, 40100 Bologna, Italy. Tel: +39 0512143255, Fax: +39 051340871, e-mail: gaetano.lamanna@unibo.it

Key Words: Anaemia, cardiovascular disease, echocardiography, haemodialysis, iron.
Patients with end stage renal disease (ESRD) are among the highest risk populations for cardiovascular disease (CVD). As depicted by the 2018 United States Renal Data System (USRDS) register (1), the prevalence of CVD in patients who received hemodialysis (HD) is $70.6 \%$. There are many changes secondary to renal dysfunction that lead to cardiac dysfunction, including fluid overload, uremic cardiomyopathy, secondary hyperparathyroidism, altered lipid metabolism, accumulation of gut microbiota-derived toxins, anemia, iron deficiency (ID) and HD (2-4). In anemic patients with chronic kidney disease (CKD), iron replacement is an established part of disease management, resulting in increased hemoglobin levels, decreased concomitant therapy with erythropoiesis-stimulating agents (ESA), and stabilized renal function (5-7). The importance of ID in cardiac heart failure (CHF) has only recently drawn clinical attention, however, several studies have shown that it could be present independently of anemia, predicts poor outcome, reduced exercise capacity and impaired quality of life (8-12). Iron plays a central role in the uptake, transport, storage and metabolism of oxygen, and it is involved in erythropoiesis and cellular immune response. According to a few studies, ID directly affects human cardiomyocyte function, impairing mitochondrial respiration, and reducing contractility and relaxation; restoration of intracellular iron levels can reverse these effects $(13,14)$. In addition, several studies have demonstrated that CKD patients who underwent ferric carboxymaltose (FCM) treatment had fewer hospitalizations for any cardiovascular cause and experienced cardiac disorders less frequently (7). Moreover, a PIVOTAL study showed that high dose FCM was associated with a lower risk of death or major adverse CVE (15).

We analyzed the effects of intravenous FCM on the anemia profile and whether it had an impact on the reduction of CVE in our HD population, on reducing ESA 
dose or on determining some cardiac modifications in a period of one year.

\section{Patients and Methods}

We performed a case-control retrospective study concerning patients undergoing hemodialysis in Policlinico Sant'Orsola and Maggiore Hospital in Bologna from September 2016 and December 2019. During our observation period, we collected demographics parameters (sex and age), clinical parameters (diabetes, hypertension, comorbidities), dialytic parameters (age of dialysis, frequency, vascular access), doses of ESA and doses of FCM.

We included all patients older than 18 years old, who performed hemodialysis for at least one year. We excluded all patients who previously received kidney transplantation, who in the previous 3 months received intravenous iron therapy and who in the last year presented an episode of coronary artery event, cerebrovascular event (stroke or TIA), de novo or relapsing CHF, or a symptomatic episode of atrial fibrillation. We did not exclude patients who presented allergies to different formulations of intravenous iron or polyallergic patients. The research was conducted ethically in accordance to the World Medical Association Declaration of Helsinki. Subjects provided written informed consent and the Local Ethical Committee approved the study.

Analysis was performed at the beginning of FCM therapy (t0) and one year later (t1), and included:

- laboratory values: Hemoglobin, mean corpuscular volume (MCV), serum iron, transferrin, ferritin, saturation of transferrin (sTF), C reactive protein (CRP), acid uric, total cholesterol, LDL, HDL, triglycerides;

- echocardiographic parameters: ejection fraction (EF), teledyastolic left atrial volume, teledyastolic interventricular septum, telesystolic interventricular septum, teledyastolic left ventricular volume, $\mathrm{E}$ wave, A wave, and E/A. Echocardiographs were performed by several cardiologists of the Cardiology Unit of Maggiore Hospital and of Policlinico Sant'Orsola.

Our population was divided into two groups, one that received FCM (study group) and one that did not (control group). FCM is a new intravenous iron preparation (molecular weight 150,000 Daltons) that comprises an iron carbohydrate complex that allows iron to be slowly released, avoiding toxicity and oxidative stress. Two $\mathrm{ml}(100 \mathrm{mg})$ of undiluted FCM was administered during the last 15-20 min of hemodialysis treatment directly in the venous circuit (16).

At one year, the role of demographic, laboratory, echocardiographic and dialytic parameters was investigated. We also analyzed the incidence of CVE expressed as a coronary artery event, cerebrovascular event (stroke or TIA), de novo or relapse of CHF, symptomatic episode of atrial fibrillation as well as the reduction of ESA.

Data were obtained from the digital medical records and a database was created specifically for the study. The study was approved by the Local Ethics Committee ( $\left.{ }^{\circ} 148 / 2019\right)$.

Statistical analysis. Quantitative data are presented as mean \pm standard deviation or as median and interquartile range (IQR) when appropriate, while qualitative data were expressed as an absolute or relative (percent) frequency. Correlations were assessed using Pearson's or Spearman's method for normally or nonnormally distributed data, respectively. The quantitative parameter distributions were analyzed by Skewness and Kustosis normality test. The chi-square test (Fisher's exact test for small numbers) was used to compare the categorical variables. Student's $t$-test and Kruskal-Wallis were used to compare quantitative parameters with a symmetric or asymmetric distribution, respectively. A $p$-value $<0.05$ was considered statistically significant. The statistical analysis was performed using STATA (Statistical software, Version 13StataCorp LP, College Station, TX, USA).

\section{Results}

Following evaluation, we selected 72 patients undergoing hemodialysis. We split our population into two groups: the study group (53 patients) that received FCM (median dose $656.6 \mathrm{mg} / \mathrm{month}$ ) and the control group (19 patients) that did not receive iron replacement therapy for clinical reasons. The study group (FCM group) included 33 men (62.3\%), and the control group (CG) $14(73.7 \%)$. The median age was $64.82 \pm 15.29$ years old and the most representative age was in the range of 61 to 80 years old. We considered the presence of diabetes (23 patients, 31.9\%) and hypertension (51 patients, 70.8\%). Regarding dialysis frequency, 61 patients $(84.7 \%)$ underwent dialysis three times per week, 9 $(12.5 \%)$ underwent dialysis twice per week and only 2 (2.8\%) patients belonging to the FCM group performed 4 dialysis per week. In our population, the mean years of dialysis were $6.15 \pm 4.51$ years. Regarding vascular access, our population included 39 patients $(54.2 \%)$ with proximal arterio-venous fistula (pAVF), $24(33.3 \%)$ with distal arteriovenous fistula (dAVF) and $9(12.5 \%)$ with central venous catheter (CVC). These results and subgroup differences are summarized in Table I.

As described above, for each patient, we evaluated laboratory results and echocardiograms performed at the beginning of FCM therapy $t(0)$ and after $12 \pm 3$ months $t(1)$. We analyzed an analogue period for the group who did not receive iron therapy.

In our population, $\mathrm{Hb}$ values of $10.44 \pm 1.77 \mathrm{~g} / \mathrm{dl}$ at $\mathrm{t}(0)$ and of $11.11 \pm 1.29 \mathrm{~g} / \mathrm{dl}$ at $\mathrm{t}(1)$ were recorded. The group that received FCM showed an increase in $\mathrm{Hb}$ of $6.79 \%$ during the study period, while the control group showed a minor increase. MCV was also evaluated considering that our patients could have a mixed anemia (normocytic and microcytic). MCV was found to be $92.8 \pm 9.7 \mathrm{fL}$ at $\mathrm{t}(0)$ and $97 \pm 8.8 \mathrm{fL}$ at $\mathrm{t}(1)$. This increasing trend occurred in both subgroups without a significative difference. CRP was also evaluated as an inflammation marker because it could influence our results; nevertheless, mean CRP values were $0.45 \pm 0.35 \mathrm{mg} / \mathrm{dl}$ at $\mathrm{t}(0)$ and $0.42 \pm 0.38 \mathrm{mg} / \mathrm{dl}$ at $\mathrm{t}(1)$ without difference between groups.

Then, we evaluated the iron balance expressed as serum iron, ferritin, transferrin, and sTF. The results are presented in Table II. In our population, serum iron was 50.3 \pm 22.3 $\mu \mathrm{g} / \mathrm{dl}$ at $\mathrm{t}(0)$ and $55.6 \pm 25.6 \mu \mathrm{g} / \mathrm{dl}$ at $\mathrm{t}(1)$. This increase was prominent in the FCM group. Furthermore, ferritin was 
Table I. Population and subgroup characteristics.

\begin{tabular}{lccc}
\hline & Population & FCM group & Control group \\
\hline $\begin{array}{l}\text { No. patients } \\
\text { Gender }\end{array}$ & 72 & 53 & 19 \\
M & & & \\
F & $47(65.3 \%)$ & $33(62.3 \%)$ & $14(73.7 \%)$ \\
Age (med \pm SD) & $64.8 \pm 15.3$ & $65(37.7 \%)$ & $5(26.3 \%)$ \\
$<40$ y & $5(6.9 \%)$ & $3(5.7 \%)$ & $64.4 \pm 15.6$ \\
$41-60$ & $18(25 \%)$ & $15(28.3 \%)$ & $3(10.5 \%)$ \\
$61-80$ & $38(52.8 \%)$ & $26(49.1 \%)$ & $12(63.2 \%)$ \\
$>80$ & $11(15.3 \%)$ & $9(17 \%)$ & $2(10.5 \%)$ \\
Diabetes & $23(31.9 \%)$ & $19(35.8 \%$ & $4(21 \%)$ \\
Hypertension & $51(70.8 \%)$ & $41(77.4 \%)$ & $10(52.6 \%)$ \\
Dialysis & & & \\
frequency/week & & & \\
2 & $9(12.5 \%)$ & $7(3.2 \%)$ & $2(10.5 \%)$ \\
3 & $61(84.7 \%)$ & $44(83 \%)$ & $17(89.7 \%)$ \\
4 & $2(2.8 \%)$ & $2(3.8 \%)$ & 0 \\
Vascular access & & & \\
pAVF & $39(54.2 \%)$ & $27(50.9 \%)$ & $12(63.2 \%)$ \\
dAVF & $24(33.3 \%)$ & $18(34 \%)$ & $6(31.6 \%)$ \\
CVC & $9(12.5 \%)$ & $8(15.1 \%)$ & $1(5.3 \%)$ \\
\hline
\end{tabular}

FCM: Ferric carboxymaltose; M: male; F: female; SD: standard deviation; y: years; pAVF: proximal arterovenous fistula; dAVF: distal arterovenous fistula; CVC: central venous catheter.

sufficient in both groups; in the whole population, mean ferritin was $302.5 \pm 398.9 \mathrm{ng} / \mathrm{ml}$ at $\mathrm{t}(0)$ and $466.7 \pm 422.6$ $\mathrm{ng} / \mathrm{ml}$ at $\mathrm{t}(1)$, showing an increase of $54.28 \%$ in the FCM group and a reduction of $8.23 \%$ in the CG. The different trend between the two groups was relevant $(p<0.001)$. As for ferritin, even sTF presented an analogous trend, increasing from $18.1 \pm 10.3 \%$ at $\mathrm{t}(0)$ to $24.2 \pm 12.9 \%$ at $\mathrm{t}(1)$. In the $\mathrm{FCM}$ group, as expected, we noticed a higher increase $(33.96 \% \mathrm{vs}$. $15.3 \%)$ with a significant difference between the two groups $(p<0.001)$ (Figure 1).

To treat anemia in CKD patients ESA are prescribed. In our population, the mean dose of ESA at $\mathrm{t}(0)$ was $19,055.6 \pm 8,226.4$ U/week whereas at $t(1)$ it was $17,111.1 \pm 9,099.69 \mathrm{U} /$ week. The variation in the dose of ESA was consistent between the two groups $(-16.8 \% v s .+3.6 \%$, $p<0.001)$

We also analyzed the relationship between iron balance and echocardiographic aspects in HD patients including the Ejection Fraction (EF, 72 patients), left atrial volume (LAV, 52 patients), left venticular telediastolic volume (LVTDV, 40 patients), and telediastolic interventricular septum diameter (SIV td, 51 patients). Then, we recorded E/A variations to investigate diastolic function. $\mathrm{E}$ wave corresponds to the rapid ventricular replacement, when after the isovolumetric release, atrial pressure exceeds the ventricular one. A wave expresses the second peak in the transmitralic pattern and corresponds to atrial systole. The E/A ratio could distinguish
Table II. Blood analysis at $t(0)$ and $t(1)$ expressed as percentage variations in one year. Significant results were observed for $s T F$, ferritin and ESA weekly dose.

\begin{tabular}{|c|c|c|c|}
\hline & FCM group & Control group & $p$-Value \\
\hline $\mathrm{Hb} \mathrm{g} / \mathrm{dl}$ & & & 0.09 \\
\hline $\mathrm{t}(0)$ & $10.6 \pm 1.4$ & $10.5 \pm 1.6$ & \\
\hline $\mathrm{t}(1)$ & $11.1 \pm 1.3$ & $11.1 \pm 1.3$ & \\
\hline$\Delta$ & $+6.5 \%$ & $+6.8 \%$ & \\
\hline $\mathrm{MCV}$ fl & & & 0.05 \\
\hline $\mathrm{t}(0)$ & $92.8 \pm 10.9$ & $93 \pm 4.8$ & \\
\hline $\mathrm{t}(1)$ & $97.2 \pm 8.7$ & $96.3 \pm 9.2$ & \\
\hline$\Delta$ & $+5.9 \%$ & $+3.7 \%$ & \\
\hline Total Cholesterol mg/dl & & & 0.3 \\
\hline $\mathrm{t}(0)$ & $157.3 \pm 66.7$ & $164.7 \pm 49$ & \\
\hline $\mathrm{t}(1)$ & $169.4 \pm 44.8$ & $152.7 \pm 45.5$ & \\
\hline$\Delta$ & $+7.67 \%$ & $-7.3 \%$ & \\
\hline LDL mg/dl & & & 0.44 \\
\hline $\mathrm{t}(0)$ & $94.5 \pm 45.6$ & $102.2 \pm 45.2$ & \\
\hline $\mathrm{t}(1)$ & $90.6 \pm 39.3$ & $88.2 \pm 39.7$ & \\
\hline$\Delta$ & $-4.09 \%$ & $-13.7 \%$ & \\
\hline HDL mg/dl & & & 0.19 \\
\hline $\mathrm{t}(0)$ & $49.8 \pm 18.1$ & $41.4 \pm 14$ & \\
\hline $\mathrm{t}(1)$ & $52.2 \pm 34.8$ & $51.6 \pm 21.7$ & \\
\hline$\Delta$ & $+4.6 \%$ & $+26.4 \%$ & \\
\hline Triglycerids mg/dl & & & 0.55 \\
\hline $\mathrm{t}(0)$ & $152.4 \pm 74$ & $158.4 \pm 57.9$ & \\
\hline $\mathrm{t}(1)$ & $151.4 \pm 44.1$ & $134.5 \pm 61.8$ & \\
\hline$\Delta$ & $-0.7 \%$ & $-15.1 \%$ & \\
\hline Uric Acid mg/dl & & & 0.06 \\
\hline $\mathrm{t}(0)$ & $6.2 \pm 0.9$ & $6.8 \pm 1.4$ & \\
\hline $\mathrm{t}(1)$ & $6.5 \pm 0.9$ & $6.8 \pm 1.4$ & \\
\hline$\Delta$ & $+6.7 \%$ & $+3.5 \%$ & \\
\hline $\mathrm{C}$ reactive Protein $\mathrm{mg} / \mathrm{dl}$ & & & 0.44 \\
\hline $\mathrm{t}(0)$ & $0.48 \pm 0.46$ & $0.39 \pm 0.27$ & \\
\hline $\mathrm{t}(1)$ & $0.45 \pm 0.38$ & $0.41 \pm 0.39$ & \\
\hline$\Delta$ & $-6 \%$ & $+5 \%$ & \\
\hline Serum iron $\mathrm{mcg} / \mathrm{dl}$ & & & 0.34 \\
\hline $\mathrm{t}(0)$ & $48.5 \pm 20$ & $55.8 \pm 27.8$ & \\
\hline $\mathrm{t}(1)$ & $55.3 \pm 25.3$ & $56.7 \pm 27.2$ & \\
\hline$\Delta$ & $+14.1 \%$ & $+1.6 \%$ & \\
\hline \multicolumn{4}{|l|}{$\operatorname{sTF}(\%)$} \\
\hline $\mathrm{t}(0)$ & $18.1 \pm 10.3$ & $19.3 \pm 10.5$ & \\
\hline $\mathrm{t}(1)$ & $24.2 \pm 12.9$ & $22.2 \pm 12.9$ & \\
\hline$\Delta$ & $34 \%$ & $15.3 \%$ & \\
\hline Ferritin ng/ml & & & $<0.001$ \\
\hline $\mathrm{t}(0)$ & $302.5 \pm 382.9$ & $532.8 \pm 1,220$ & \\
\hline $\mathrm{t}(1)$ & $466.7 \pm 422.6$ & $489 \pm 1,341.3$ & \\
\hline$\Delta$ & $54 \%$ & $-8 \%$ & \\
\hline ESA dose U/week & & & $<0.001$ \\
\hline $\mathrm{t}(0)$ & $17,547.2 \pm 6,931.2$ & $23,263.2 \pm 10,137.1$ & \\
\hline$t(1)$ & $14,603.8 \pm 7,641.8$ & $24,105.3 \pm 9,368.4$ & \\
\hline$\Delta$ & $-16.8 \%$ & $+3.6 \%$ & \\
\hline
\end{tabular}

FCM: Ferric carboxymaltose; Hb: Haemoglobin; ESA: erythropoiesisstimulating agents; sTF: transferrin saturation MCV: mean corpuscolar volume; LDL: low density lipoprotein; HDL: high density lipoprotein.

4 diastolic patterns of trans-mitralic flux: normal, altered diastolic release, pseudonormal pattern and restrictive pattern. In our population, E/A was available for 28 patients. 


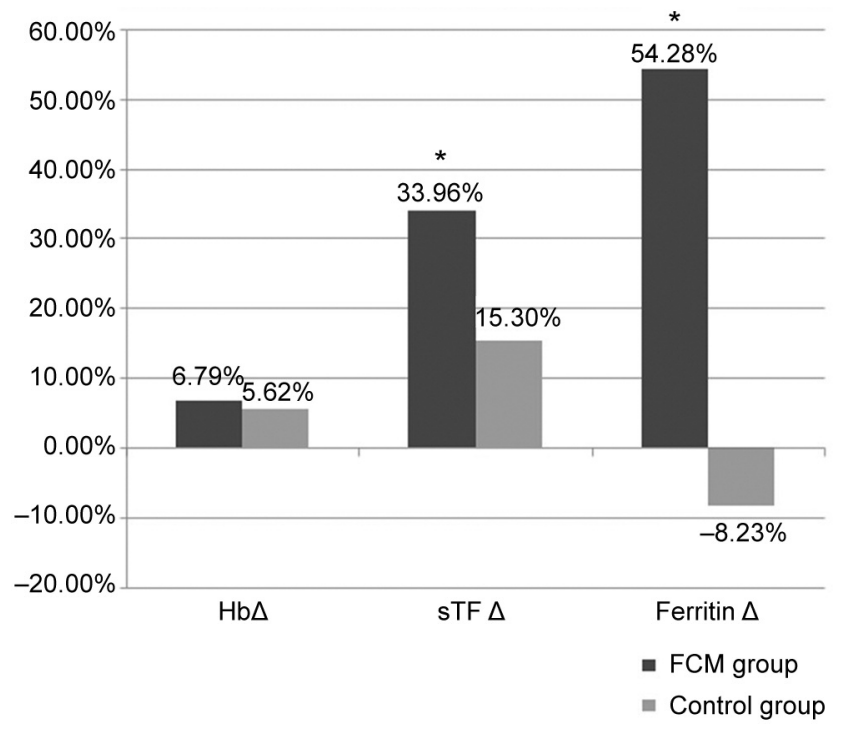

Figure 1. Changes in $\mathrm{Hb}, \mathrm{sTF}$ and ferritin after one-year observation between the two groups. STF and ferritin showed a significant increase in the group receiving FCM vs. the control group. Hb: Hemoglobin; sTF: transferrin saturation; FCM: ferric carboxymaltose.

Although we observed several differences between the two groups, no significant variations were recorded in our echocardiographic values (Table III).

Similarly to recent studies, we examined whether FCM therapy in our population could reduce the incidence of cardiovascular events (CVE); therefore, we evaluated coronary artery event (CA), cerebrovascular event (stroke or TIA), de novo or relapse of CHF, symptomatic episode of atrial fibrillation (AF). In the whole population, we observed 18 CVE in 15 patients (20.83\%), $10 \mathrm{CA}, 2 \mathrm{AF}, 5 \mathrm{CHF}$, and 1 stroke. Analyzing the FCM group, we witnessed $9 \mathrm{CVE}$ $(16.98 \%)$ in 7 patients, $5 \mathrm{CA}(9.43 \%)$ in 5 patients, $2 \mathrm{AF}$ $(3.77 \%)$ in 2 patients, $1 \mathrm{CHF}(1.89 \%)$ and 1 stroke $(1.89 \%)$. In this population, 2 patients $(3.77 \%)$ presented multiple CVE in the considered period. Considering the CG, we also witnessed $9 \mathrm{CVE}(47.37 \%)$ in 8 patients, $5 \mathrm{CA}(26.32 \%)$ in 5 patients, no $\mathrm{AF}, 4 \mathrm{CHF}(21.05 \%)$ in 4 patients and no strokes. The difference in the incidence of CVE and CA was statistically significantly different between the two groups $(p<0.02, p<0.02)$. The distribution of CVE is shown in Figure 2. Then, we examined whether some conditions could influence our results but no statistical significance was reached among the different subgroups (Table IV).

\section{Discussion}

Anemia in HD patients has complex and multiple etiologies and significantly impairs quality of life. Several previous studies have shown that anemia is associated with higher risk
Table III. Echocardiographic parameters of the two populations with percentage changes in one year. No significative results were obtained although differences were observed.

\begin{tabular}{cccc}
\hline & FCM group & Control group & $p$-Value \\
\hline EF & & & \\
$\mathrm{t}(0)$ & $55.9 \%$ & $60.9 \%$ & \\
$\mathrm{t}(1)$ & $56.5 \%$ & $60.9 \%$ & \\
$\Delta$ & $+1.05 \%$ & $+0.1 \%$ & 0.8 \\
LAV & & & \\
$\mathrm{t}(0)$ & $59.3 \mathrm{mmc}$ & $42.1 \mathrm{mmc}$ & \\
$\mathrm{t}(1)$ & $59.6 \mathrm{mmc}$ & $44.4 \mathrm{mmc}$ & \\
$\Delta$ & $+0.49 \%$ & $+3.92 \%$ & 0.3 \\
LVTDV & & & \\
$\mathrm{t}(0)$ & $112.9 \mathrm{ml}$ & $114.9 \mathrm{ml}$ & \\
$\mathrm{t}(1)$ & $109.3 \mathrm{ml}$ & $94.5 \mathrm{ml}$ & \\
$\Delta$ & $-3.16 \%$ & $-17.64 \%$ & 0.09 \\
SIV td & & & \\
$\mathrm{t}(0)$ & $12.5 \mathrm{~mm}$ & $12.1 \mathrm{~mm}$ & \\
$\mathrm{t}(1)$ & $13.1 \mathrm{~mm}$ & $12.2 \mathrm{~mm}$ & \\
$\Delta$ & $+5.23 \%$ & $+0.1 \%$ & 0.78 \\
$\mathrm{E} / \mathrm{A}$ & & & \\
$\mathrm{t}(0)$ & 1.03 & 1.18 & \\
$\mathrm{t}(1)$ & 0.99 & 0.8 & \\
$\Delta$ & $-4.44 \%$ & $-36.36 \%$ & 0.07 \\
\hline
\end{tabular}

EF: Ejection fraction; LAV: left atrial volume; LVTDV: left ventricular telediastolic volume; SIV td: telediastolic interventricular septum.

of left ventricular hypertrophy, CVE, hospitalization and death (17-19). It is currently known that a lot of HD patients present iron deficiency because of reduced dietary intake, reduced gut absorption and increased gastrointestinal iron losses $(20,21)$. Intravenous iron replacement is often required for these patients in order to reduce ESA doses and to reach adequate $\mathrm{Hb}$ values; nevertheless, concerns have been raised regarding the safety of iron compounds due to the possibility of iron overload, oxidative stress, cardiovascular disease and hypersensitivity reactions (22, 23). On the other hand, even ESA therapy could result in many adverse clinical consequences such as stroke and venous thromboembolic disease, and some patients do not respond adequately to ESA (24-26).

In line with the NICE guidelines (27) and KDIGO recommendations on anemia management, our population received FCM therapy and showed no side effects or hypersensibility reactions. None of our patients dismissed the therapy due to iron overload and we did not purposely exclude from our analysis patients who presented anamnestic iron reactions.

A significant difference in terms of CVE was observed between the group treated with FCM $v s$. the CG. Our results are in line with the study of Garcia et al. (28), who showed that high ESA dose is an independent predictor for all-cause, CVE and infectious hospitalization. The study focused on the 


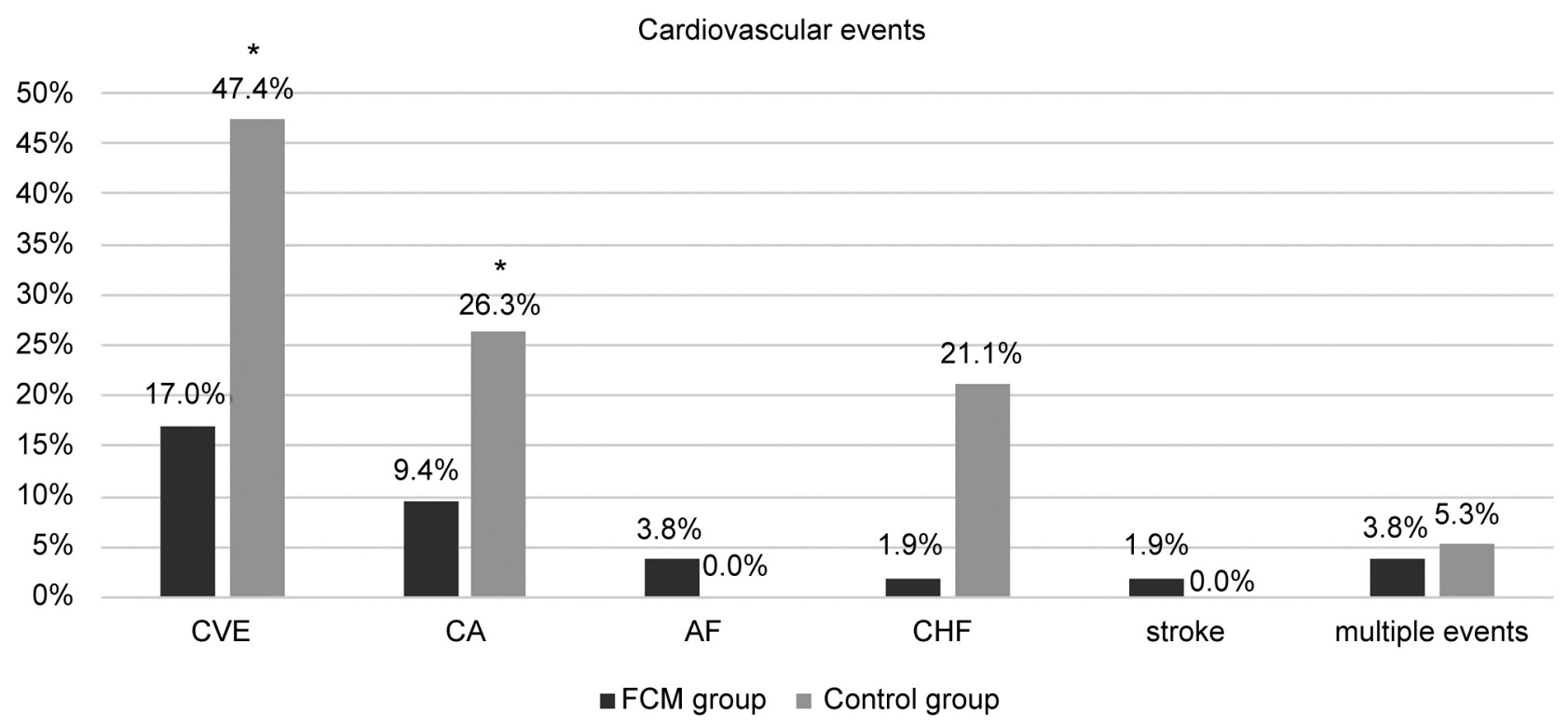

Figure 2. Cardiovascular events in the two groups after one-year observation. Significant results were observed for cardiovascular events (CVE) and coronary artery disease (CA). AF: Atrial fibrillation; CHF: cardiac heart failure; FCM: ferric carboxymaltose.

increase in mortality with a higher dose of ESA $(>8,000$ IU/week). As the authors suggested, we hypothesized that the dose sparing effect of intravenous iron therapy on ESA might contribute to the cardiovascular profile; our population received a higher mean dose of ESA than the one in that study, and the FCM group showed a decrease in the number of CVE compared to the CG, supporting the reduction in the dose of ESA.

Apart from its role in maintaining the oxygen-carrying capacity of the blood in erythropoiesis, iron is independently crucial for oxygen transport, delivery and utilization. Metabolically active cells (as myocytes) depend on iron for their function and structural integrity (29-31). Iron deficiency is prevalent in CHF and may be present independently of anemia; it predicts poor outcomes, reduces exercise capacity, and impairs quality of life $(32,33)$, however, though those studies were performed in patients who were not on HD. A study that set a milestone in the scientific community, was performed by Mcdougall et al. (15). In a population of over 2,000 patients undergoing HD, they showed that those who received a proactive dose (high dose, $200-400 \mathrm{mg} / \mathrm{month}$ ) rather than a reactive dose (low dose, $<200 \mathrm{mg} / \mathrm{month}$ ) of FCM presented a significative reduction in the composite end-point (nonfatal myocardial infarction, nonfatal stroke, hospitalization for heart failure or death, assessed in a time to first event analysis). Our population received a higher dose of FCM (656.6 $\mathrm{mg} / \mathrm{month}$ ), without any adverse event. Supported by the data of the PIVOTAL study, we found that patients who received FCM had a reduced number of CVE compared to those who did not. Moreover, CVE among patients who received $800 \mathrm{mg} / \mathrm{month}$ were slightly inferior compared to those who received less than $400 \mathrm{mg} / \mathrm{month}$.

Our cohort reached high levels of ferritin and sTF, showing no increase of CVE during the year; however, one year of observation is a short period of time which does not allow us to reach definite conclusions, and does not take into account the accumulation of iron in tissues. Despite not reaching statistical significance, the highest number of CVE in our cohort was observed in the CG, with levels of ferritin $<200 \mathrm{ng} / \mathrm{ml}$.

Regarding sTF, without reaching statistical significance, we evidenced most CVE in those who presented low levels in both groups compared to those who reached satisfactory values. Our results are in line with a study by Fukuma et al. where values of ferritin $<200 \mathrm{ng} / \mathrm{ml}$ and $\mathrm{sTF}<20 \%$ were associated with increased cardiovascular mortality (34).

We analyzed the correlation between vascular access and the incidence of CVE. The arteriovenous fistula (AVF) undoubtedly contributes to inflammation status, excess CV mortality in HD patients and a short life span (35-37). As described by Basile et al. (38), significant hemodynamic modifications of the cardiovascular system are associated with AVF. To our knowledge, there are no studies that correlate an improved iron balance, to specific hemodynamic modifications in HD patients; with this in mind, we analyzed the echocardiograms of our population. We noticed multiple changes in echocardiographic parameters in the FCM group compared to the CG. The most improved parameter was ejection fraction (EF) that showed an improvement in the 
Table IV. Number of cardiovascular events in the two subpopulations. Differences were significant for CVE and CA.

\begin{tabular}{|c|c|c|c|c|}
\hline & $\begin{array}{c}\text { Number of } \\
\text { patients }\end{array}$ & Population & $\begin{array}{l}\text { FCM } \\
\text { group }\end{array}$ & $\begin{array}{c}\text { Control } \\
\text { group }\end{array}$ \\
\hline Diabetes & 23 & 3 & 2 & 1 \\
\hline Hypertension & 51 & 12 & 8 & 4 \\
\hline \multicolumn{5}{|l|}{ Dialysis frequency } \\
\hline 2 & 9 & 0 & 0 & 0 \\
\hline 3 & 61 & 15 & 6 & 9 \\
\hline 4 & 2 & 3 & & \\
\hline \multicolumn{5}{|l|}{ Years of dialysis } \\
\hline$<5$ & 34 & 7 & 4 & 3 \\
\hline $5<$ years $<10$ & 26 & 7 & 1 & 6 \\
\hline$>10$ & 12 & 4 & 4 & \\
\hline \multicolumn{5}{|l|}{ Vascular access } \\
\hline pAVF & 39 & 9 & 3 & 6 \\
\hline dAVF & 24 & 5 & 3 & 2 \\
\hline $\mathrm{CVC}$ & 9 & 4 & 3 & 1 \\
\hline \multicolumn{5}{|l|}{ Mean FCM (mg/week) } \\
\hline$<400$ & 28 & 6 & 6 & \\
\hline $400<\mathrm{FCM}<800$ & 16 & 3 & 3 & \\
\hline$>800$ & 8 & 0 & 0 & \\
\hline \multicolumn{5}{|l|}{$\begin{array}{l}\text { Mean ESA dose } \\
\text { (U/week) }\end{array}$} \\
\hline$<10,000$ & 16 & 1 & 1 & 0 \\
\hline $10,000<\mathrm{ESA}<20,000$ & 28 & 8 & 4 & 4 \\
\hline$>20,000$ & 28 & 9 & 4 & 5 \\
\hline \multicolumn{5}{|l|}{ Mean $\mathrm{Hb}(\mathrm{g} / \mathrm{dl})$} \\
\hline$<10.5 \mathrm{~g} / \mathrm{dl}$ & 28 & 12 & 5 & 7 \\
\hline $10.5<\mathrm{Hb}<11.5$ & 29 & 4 & 2 & 2 \\
\hline$>11.5$ & 15 & 2 & 2 & 0 \\
\hline \multicolumn{5}{|l|}{ Mean sTF (\%) } \\
\hline$<20$ & 37 & 14 & 7 & 7 \\
\hline $20<\mathrm{sTF}<45$ & 32 & 3 & 2 & 1 \\
\hline$>45$ & 3 & 1 & 0 & 1 \\
\hline \multicolumn{5}{|l|}{ Mean Ferritin (ng/ml) } \\
\hline$<200$ & 33 & 8 & 3 & 5 \\
\hline $200<$ Ferritin $<800$ & 33 & 9 & 6 & 3 \\
\hline$>800$ & 6 & 1 & 0 & 1 \\
\hline
\end{tabular}

FCM: Ferric carboxymaltose; pAVF: proximal arteriovenous fistula; dAVF: distal arteriovenous fistula; CVC: central venous catheter, ESA: erythropoiesis stimulating agents; Hb: Haemoglobin; sTF: transferrin saturation.

FCM group compared with the CG (2.38\% vs. $0.09 \%)$. Another improved parameter was SIVtd where a greater improvement was observed in the FCM group $(4.52 \%$ vs. $1.76 \%$ ). In the FCM group, most of CVE and CA occurred in those who presented EF $<50 \%$. Naturally, those parameters could not provide an all-round assessment of systolic function in HD patients, and due to the retrospective character of this study, it is difficult to derive conclusions. Despite this drawback, we suggest that an improvement in EF in these patients could reflect an improvement in systolic function.

Amerling and Ronco (37), examined the hemodynamic effects of AVF and concluded that it decreases peripheral resistance, and increases cardiac output, sympathetic activity with increased contractility, heart rate, stroke volume, blood volume with increased left ventricular end diastolic dimension, and pulmonary flow; overtime there is cardiac hypertrophy and four-chamber enlargement that can lead to diastolic dysfunction (39, 40). Concerning diastolic disfunction, in our cohort, LVTDV had a significant decrease only in $\mathrm{CG}$ and the left atrial volume was increased only in the CG. A moderate to severe dilatation of left atrial volume, as suggested by Di Tullio et al. (41), is related to an increase in all causes of mortality, mortality from CVE, and to hospitalizations for HF. Therefore, despite the fact that these results were obtained from a small number of patients, E/A index increased in the FCM group and decreased in the $\mathrm{CG}$; E/A index together with tissue doppler, can distinguish 4 transmitral flux patterns: normal, altered released, pseudonormalized and restrictive (42). Due to these results, we predicted an incipient diastolic dysfunction that progressed more rapidly in the CG $v s$. the FCM group.

Finally, due to the retrospective character of the study, it is difficult to derive conclusions from echocardiographic parameters. Additional studies need to be performed in order to confirm whether intravenous iron therapy could improve systolic and diastolic disfunction in HD patients.

In conclusion, we demonstrated that FCM therapy had a beneficial impact on CVE in a HD population and helped reach satisfactory levels of $\mathrm{Hb}$, ferritin, and sTF. Importantly it helped reduce the dose of ESA compared to those who did not receive the FCM therapy. Echocardiography could be a useful tool for identifying progressive CVD in HD patients.

\section{Conflicts of Interest}

The Authors declare no conflicts of interest in relation to this study.

\section{Authors' Contributions}

Matteo Righini: contributed to study design, data collection, data analysis and article writing. Vittorio Dalmastri: contributed to study design and data collection. Irene Capelli: contributed to study design, data analysis and paper writing. Claudio Orsi: contributed to data collection and reference collection. Gabriele Donati: contributed to article writing and final revision. Maria Giovanna Pallotti: contributed to echocardiography description and article writing. Chiara Pedone: contributed to echocardiography description. Gianni Casella: contributed to manuscript revision. Pasquale Chieco: contributed to statistical analysis. Gaetano La Manna: contributed to study design, manuscript revision and data interpretation. Each Author contributed important intellectual content during manuscript drafting or revision, accepts personal accountability for the author's own contributions, and agrees to ensure that questions pertaining to the accuracy or integrity of any portion of the work are appropriately investigated and resolved. 


\section{References}

12018 USRDS Annual data report. Volume 2: ESRD in the United States, Chapter 8: Cardiovascular disease in patients with ESRD, pp. 501- 518, 2018

2 Ahmadmehrabi S and Tang WHW: Hemodialysis-induced cardiovascular disease. Semin Dial 31(3): 258-267, 2018. PMID: 29624739. DOI: $10.1111 /$ sdi.12694

3 Foley RN, Parfrey PS, Harnett JD, Kent GM, Murray DC and Barre PE: The impact of anemia on cardiomyopathy, morbidity, and and mortality in end-stage renal disease. Am J Kidney Dis 28(1): 53-61, 1996. PMID: 8712222. DOI: 10.1016/s02726386(96)90130-4

4 Wish JB, Aronoff GR, Bacon BR, Brugnara C, Eckardt KU, Ganz T, Macdougall IC, Núñez J, Perahia AJ and Wood JC: Positive iron balance in chronic kidney disease: How much is too much and how to tell? Am J Nephrol 47(2): 72-83, 2018. PMID: 29439253. DOI: 10.1159/000486968

5 KDOQ and National Kidney Foundation: II. Clinical practice guidelines and clinical practice recommendations for anemia in chronic kidney disease in adults. Am J Kidney Dis 47(5 Suppl 3): S16-S85, 2006. PMID: 16678661. DOI: 10.1053/j.ajkd.2006.03.011

6 Mircescu G, Gârneata L, Capusa C and Ursea N: Intravenous iron supplementation for the treatment of anaemia in pre-dialyzed chronic renal failure patients. Nephrol Dial Transplant 21(1): 120-124, 2006. PMID: 16144853. DOI: 10.1093/ndt/gfi087

7 Ponikowski P, Filippatos G, Colet JC, Willenheimer R, Dickstein K, Lüscher T, Gaudesius G, von Eisenhart Rothe B, Mori C, Greenlaw N, Ford I, Macdougall I, Anker SD and FAIR-HF Trial Investigators: The impact of intravenous ferric carboxymaltose on renal function: An analysis of the FAIR-HF study. Eur J Heart Fail 17(3): 329-339, 2015. PMID: 25683972. DOI: 10.1002/ejhf.229

8 Comín-Colet J, Enjuanes C, González G, Torrens A, Cladellas M, Meroño O, Ribas N, Ruiz S, Gómez M, Verdú JM and Bruguera J: Iron deficiency is a key determinant of healthrelated quality of life in patients with chronic heart failure regardless of anaemia status. Eur J Heart Fail 15(10): 1164-1172, 2013. PMID: 23703106. DOI: 10.1093/eurjhf/hft083

9 Enjuanes C, Klip IT, Bruguera J, Cladellas M, Ponikowski P, Banasiak W, van Veldhuisen DJ, van der Meer P, Jankowska EA and Comín-Colet J: Iron deficiency and health-related quality of life in chronic heart failure: results from a multicenter European study. Int J Cardiol 174(2): 268-275, 2014. PMID: 24768464. DOI: $10.1016 /$ j.ijcard.2014.03.169

10 Jankowska EA, Rozentryt P, Witkowska A, Nowak J, Hartmann O, Ponikowska B, Borodulin-Nadzieja L, von Haehling S, Doehner W, Banasiak W, Polonski L, Filippatos G, Anker SD and Ponikowski P: Iron deficiency predicts impaired exercise capacity in patients with systolic chronic heart failure. J Card Fail 17(11): 899-906, 2011. PMID: 22041326. DOI: 10.1016/ j.cardfail.2011.08.003

11 Okonko DO, Mandal AK, Missouris CG and Poole-Wilson PA: Disordered iron homeostasis in chronic heart failure: Prevalence, predictors, and relation to anemia, exercise capacity, and survival. J Am Coll Cardiol 58(12): 1241-1251, 2011. PMID: 21903058. DOI: 10.1016/j.jacc.2011.04.040

12 van Veldhuisen DJ, Anker SD, Ponikowski P and Macdougall IC: Anemia and iron deficiency in heart failure: mechanisms and therapeutic approaches. Nat Rev Cardiol 8(9): 485-493, 2011. PMID: 21629210. DOI: 10.1038/nrcardio.2011.77
13 Dziegala M, Josiak K, Kasztura M, Kobak K, von Haehling S, Banasiak W, Anker SD, Ponikowski P and Jankowska E: Iron deficiency as energetic insult to skeletal muscle in chronic diseases. J Cachexia Sarcopenia Muscle 9(5): 802-815, 2018. PMID: 30178922. DOI: 10.1002/jcsm.12314

14 Hoes MF, Grote Beverborg N, Kijlstra JD, Kuipers J, Swinkels DW, Giepmans BNG, Rodenburg RJ, van Veldhuisen DJ, de Boer RA and van der Meer P: Iron deficiency impairs contractility of human cardiomyocytes through decreased mitochondrial function. Eur J Heart Fail 20(5): 910-919, 2018. PMID: 29484788. DOI: 10.1002/ejhf.1154

15 Macdougall IC, White C, Anker SD, Bhandari S, Farrington K, Kalra PA, McMurray JJV, Murray H, Tomson CRV, Wheeler DC, Winearls CG, Ford I and PIVOTAL Investigators and Committees: Intravenous iron in patients undergoing maintenance hemodialysis. N Engl J Med 380(5): 447-458, 2019. PMID: 30365356. DOI: 10.1056/NEJMoa 1810742

16 Geisser P: The pharmacology and safety profile of ferric carboxymaltose (Ferinject): structure/reactivity relationships of iron preparations. Port J Nephrol Hypert 23(1): 11-16, 2009.

17 Volkova N and Arab L: Evidence-based systematic literature review of hemoglobin/hematocrit and all-cause mortality in dialysis patients. Am J Kidney Dis 47(1): 24-36, 2006. PMID: 16377382. DOI: 10.1053/j.ajkd.2005.09.007

18 Locatelli F, de Francisco A, Deray G, Fliser D, Armstrong G, Dougherty FC and Ehrhard P: Mortality and cardiovascular morbidity associated with haemoglobin levels: A pooled analysis of randomised controlled trials. Nephron Clin Pract 128(3-4): 323-332, 2014. PMID: 25503585. DOI: 10.1159/000366478

19 Drozdz M, Weigert A, Silva F, Frazão J, Alsuwaida A, Krishnan M, Kleophas W, Brzosko S, Johansson FK and Jacobson SH: Achievement of renal anemia KDIGO targets by two different clinical strategies - a European hemodialysis multicenter analysis. BMC Nephrol 20(1): 5, 2019. PMID: 30616548. DOI: 10.1186/s12882-018-1196-7

20 Nangaku M and Eckardt KU: Pathogenesis of renal anemia. Semin Nephrol 26(4): 261-268, 2006. PMID: 16949463. DOI: 10.1016/j.semnephrol.2006.06.001

21 Flint S, Taylor E, Beavis J, Becker GJ and Pedagogos E: Increased iron requirement in hemodialysis patients on antiplatelet agents or warfarin. Nephron Clin Pract 113(1): c38c45, 2009. PMID: 19590234. DOI: 10.1159/000228074

22 Rampton D, Folkersen J, Fishbane S, Hedenus M, Howaldt S, Locatelli F, Patni S, Szebeni J and Weiss G: Hypersensitivity reactions to intravenous iron: Guidance for risk minimization and management. Haematologica 99(11): 1671-1676, 2014. PMID: 25420283. DOI: 10.3324/haematol.2014.111492

23 Tovbin D, Mazor D, Vorobiov M, Chaimovitz C and Meyerstein $\mathrm{N}$ : Induction of protein oxidation by intravenous iron in hemodialysis patients: Role of inflammation. Am J Kidney Dis 40(5): 1005-1012, 2002. PMID: 12407646. DOI: 10.1053/ ajkd.2002.36334

24 Lee YK, Koo JR, Kim JK, Park II, Joo MH, Yoon JW, Noh JW and Vaziri ND: Effect of route of EPO administration on hemodialysis arteriovenous vascular access failure: A randomized controlled trial. Am J Kidney Dis 53(5): 815-822, 2009. PMID: 19324483. DOI: 10.1053/j.ajkd.2008.12.035

25 Kalantar-Zadeh K, Lee GH, Miller JE, Streja E, Jing J, Robertson JA and Kovesdy CP: Predictors of hyporesponsiveness to erythropoiesis-stimulating agents in hemodialysis patients. Am J 
Kidney Dis 53(5): 823-834, 2009. PMID: 19339087. DOI: 10.1053/j.ajkd.2008.12.040

26 Rossert J, Gassmann-Mayer C, Frei D and McClellan W: Prevalence and predictors of epoetin hyporesponsiveness in chronic kidney disease patients. Nephrol Dial Transplant 22(3): 794-800, 2007. PMID: 17210593. DOI: $10.1093 / \mathrm{ndt} / \mathrm{gfl} 116$

27 Ratcliffe LE, Thomas W, Glen J, Padhi S, Pordes BA, Wonderling D, Connell R, Stephens S, Mikhail AI, Fogarty DG, Cooper JK, Dring B, Devonald MA, Brown C and Thomas ME: Diagnosis and management of iron deficiency in CKD: A summary of the NICE guideline recommendations and their rationale. Am J Kidney Dis 67(4): 548-558, 2016. PMID: 26763385. DOI: 10.1053/j.ajkd.2015.11.012

28 Pérez-García R, Varas J, Cives A, Martín-Malo A, Aljama P, Ramos R, Pascual J, Stuard S, Canaud B, Merello JI and ORD group: Increased mortality in haemodialysis patients administered high doses of erythropoiesis-stimulating agents: A propensity score-matched analysis. Nephrol Dial Transplant 33(4): 690-699, 2018. PMID: 29036505. DOI: 10.1093/ndt/ gfx269

29 Anand IS and Gupta P: Anemia and iron deficiency in heart failure: Current concepts and emerging therapies. Circulation 138(1): 80-98, 2018. PMID: 29967232. DOI: 10.1161/ CIRCULATIONAHA.118.030099

30 Melenovsky V, Petrak J, Mracek T, Benes J, Borlaug BA, Nuskova H, Pluhacek T, Spatenka J, Kovalcikova J, Drahota Z, Kautzner J, Pirk J and Houstek J: Myocardial iron content and mitochondrial function in human heart failure: A direct tissue analysis. Eur J Heart Fail 19(4): 522-530, 2017. PMID: 27647766. DOI: 10.1002/ejhf.640

31 Jankowska EA and Ponikowski P: Molecular changes in myocardium in the course of anemia or iron deficiency. Heart Fail Clin 6(3): 295-304, 2010. PMID: 20630404. DOI: 10.1016/ j.hfc.2010.03.003

32 Anker SD, Comin Colet J, Filippatos G, Willenheimer R, Dickstein K, Drexler H, Lüscher TF, Bart B, Banasiak W, Niegowska J, Kirwan BA, Mori C, von Eisenhart Rothe B, Pocock SJ, Poole-Wilson PA, Ponikowski P and FAIR-HF Trial Investigators: Ferric carboxymaltose in patients with heart failure and iron deficiency. N Engl J Med 361(25): 2436-2448, 2009. PMID: 19920054. DOI: 10.1056/NEJMoa0908355

33 Ponikowski P, van Veldhuisen DJ, Comin-Colet J, Ertl G, Komajda M, Mareev V, McDonagh T, Parkhomenko A, Tavazzi L, Levesque V, Mori C, Roubert B, Filippatos G, Ruschitzka F, Anker SD and CONFIRM-HF Investigators: Beneficial effects of long-term intravenous iron therapy with ferric carboxymaltose in patients with symptomatic heart failure and iron deficiency $\dagger$. Eur Heart J 36(11): 657-668, 2015. PMID: 25176939. DOI: 10.1093/eurheartj/ehu385
34 Fukuma S, Yamaguchi T, Hashimoto S, Nakai S, Iseki K, Tsubakihara Y and Fukuhara S: Erythropoiesis-stimulating agent responsiveness and mortality in hemodialysis patients: Results from a cohort study from the dialysis registry in Japan. Am J Kidney Dis 59(1): 108-116, 2012. PMID: 21890255. DOI: 10.1053/j.ajkd.2011.07.014

35 Colì L, Donati G, Cappuccilli ML, Cianciolo G, Comai G, Cuna V, Carretta E, La Manna G and Stefoni S: Role of the hemodialysis vascular access type in inflammation status and monocyte activation. Int J Artif Organs 34(6): 481-488, 2011. PMID: 21725929. DOI: 10.5301/IJAO.2011.8466

36 Amerling R: Fistula First: Is it time to curb our enthusiasm? Nephrol News Issues 20(9): 38-39, 2006. PMID: 16916060.

37 Amerling R, Ronco C, Kuhlman $\mathrm{M}$ and Winchester JF: Arteriovenous fistula toxicity. Blood Purif 31(1-3): 113-120, 2011. PMID: 21228578. DOI: $10.1159 / 000322695$

38 Basile C, Vernaglione L, Casucci F, Libutti P, Lisi P, Rossi L, Vigo $\mathrm{V}$ and Lomonte $\mathrm{C}$ : The impact of haemodialysis arteriovenous fistula on haemodynamic parameters of the cardiovascular system. Clin Kidney J 9(5): 729-734, 2016. PMID: 27679720. DOI: 10.1093/ckj/sfw063

39 Nakhoul F, Yigla M, Gilman R, Reisner SA and Abassi Z: The pathogenesis of pulmonary hypertension in haemodialysis patients via arterio-venous access. Nephrol Dial Transplant 20(8): 1686-1692, 2005. PMID: 15840664. DOI: 10.1093/ ndt/gfh 840

40 von Bibra H, Castro L, Autenrieth G, McLeod A and Gurland HJ: The effects of arteriovenous shunts on cardiac function in renal dialysis patients-an echocardiographic evaluation. Clin Nephrol 9(5): 205-209, 1978. PMID: 657597.

41 Di Tullio MR, Qian M, Thompson JLP, Labovitz AJ, Mann DL, Sacco RL, Pullicino PM, Freudenberger RS, Teerlink JR, Graham S, Lip GYH, Levin B, Mohr JP, Buchsbaum R, Estol CJ, Lok DJ, Ponikowski P, Anker SD, Homma S and WARCEF Investigators: Left atrial volume and cardiovascular outcomes in systolic heart failure: Effect of antithrombotic treatment. ESC Heart Fail 5(5): 800-808, 2018. PMID: 30015405. DOI: 10.1002/ehf2.12331

42 Garcia MJ, Ares MA, Asher C, Rodriguez L, Vandervoort P and Thomas JD: An index of early left ventricular filling that combined with pulsed Doppler peak E velocity may estimate capillary wedge pressure. J Am Coll Cardiol 29(2): 448-454, 1997. PMID: 9015003. DOI: 10.1016/s0735-1097(96)00496-2

Received February 27, 2021

Revised March 12, 2021

Accepted March 23, 2021 